\title{
Fast Inhibition Underlies the Transmission of Auditory Information between Cochlear Nuclei
}

\author{
Karina Needham, ${ }^{1}$ and Antonio G. Paolini ${ }^{2,3}$ \\ ${ }^{1}$ Department of Otolaryngology, The University of Melbourne, East Melbourne, Victoria 3002, Australia, ${ }^{2}$ The Bionic Ear Institute, East Melbourne, Victoria \\ 3002, Australia, and ${ }^{3}$ School of Psychological Science, La Trobe University, Bundoora, Victoria 3086, Australia
}

\begin{abstract}
A direct commissural connection between cochlear nuclei provides a pathway by which binaural input can influence the processing of acoustic information through the ventral cochlear nucleus. Despite anatomical evidence to suggest the existence of such a pathway, its nature and behavior have not been investigated previously. This in vivo intracellular electrophysiological study provides direct evidence of monosynaptic (mean latency, $1.43 \mathrm{msec}$ ), inhibitory commissural input to T stellate cells. This inhibition is fast acting (duration, $<10$ $\mathrm{msec})$, occurring with little synaptic delay $(\sim 0.3 \mathrm{msec})$. Electrical stimulation also revealed the initiation of antidromic responses in the onset chopper population, signifying D stellate neurons as a source of commissural inputs. Activation of the commissural connection was most evident in response to broadband stimuli. These results provide the first compelling evidence of a fast, monosynaptic commissural pathway arising from contralateral $\mathrm{D}$ stellate neurons providing broadband inhibitory input to $\mathrm{T}$ stellate cells.
\end{abstract}

Key words: ventral cochlear nucleus; commissural connection; stellate neurons; inhibition; in vivo intracellular electrophysiology; antidromic action potential

\section{Introduction}

The cochlear nucleus $(\mathrm{CN})$ complex, as the first brain center of the ascending auditory pathway, serves to process information received from the cochlea into numerous parallel processing streams for transmission to higher central auditory nuclei (Young, 1998). One such pathway is through the stellate (multipolar) population of the ventral $\mathrm{CN}(\mathrm{VCN})$, a population divided into $\mathrm{T}$ and $\mathrm{D}$ stellate cells on the basis of dendritic morphology and axonal projections (Oertel et al., 1990). One auditory nuclei thought to receive projections from the stellate population is the contralateral VCN (Cant and Gaston, 1982; Schofield and Cant, 1996a,b; Alibardi, 1998, 2000). Although VCN neurons are known to receive efferent input from higher auditory centers, a commissural connection between contralateral and ipsilateral $\mathrm{CN}$ providing direct bilateral input to the VCN has remained contentious.

Speculation has surrounded the existence of this pathway because studies revealed contralateral acoustic stimulation as capable of inhibiting and exciting cells throughout the CN (Pfalz, 1962; Klinke et al., 1969; Mast, 1970, 1973; Young and Brownell, 1976). Whereas the latency of such acoustically driven responses (8-500 $\mathrm{msec}$ ) was indicative of indirect, polysynaptic pathways, anatomical studies (Cant and Gaston, 1982; Wenthold, 1987; Shore et al., 1992; Schofield and Cant, 1996a,b; Alibardi, 2000) have since demonstrated direct inhibitory projections between the two CN. Despite providing little information on its strength and functional consequences, anatomical studies proposed large

\footnotetext{
Received April 11, 2003; revised May 19, 2003; accepted May 20, 2003.

This work was supported by a Melbourne Research Scholarship (The University of Melbourne) and The Bionic Ear Institute. We thank J. C. Clarey for suggestions and comments regarding experiments and this manuscript, R. E. Millard for technical assistance, and G. M. Clark for encouragement and support.

Correspondence should be addressed to A. G. Paolini, School of Psychological Science, La Trobe University, Bundoora, Victoria 3086, Australia. E-mail: a.paolini@latrobe.edu.au.

Copyright $\odot 2003$ Society for Neuroscience $\quad 0270-6474 / 03 / 236357-05 \$ 15.00 / 0$
}

multipolar cells, correlating to the D stellate population, as the source of commissural projections (Cant and Gaston, 1982; Schofield and Cant, 1996a,b; Alibardi, 2000) and nominated T stellate neurons as the principal recipients (Schofield and Cant, 1996a,b). Although recent in vitro studies by Babalian et al. (1999, 2002) have demonstrated contralaterally mediated inhibition using intracellular recordings, they could provide few clues to the time course or strength of IPSPs, nor could they differentiate monosynaptic and polysynaptic influences.

In this study, we examine the commissural connection through in vivo intracellular and extracellular electrophysiological recordings in the rat. Our investigation explores the influence of direct commissural input on the ipsilateral VCN through electrical and acoustic stimulation of the contralateral CN. Of particular interest is the role of the stellate populations. Thus, we report on the effects of contralateral stimulation on onset chopper $\left(\mathrm{O}_{\mathrm{C}}\right)$ and chopper [sustained $\left(\mathrm{C}_{\mathrm{S}}\right)$ and transient $\left(\mathrm{C}_{\mathrm{T}}\right)$ ] neurons, the physiological response patterns displayed by $\mathrm{D}$ and T stellate cells, respectively (Blackburn and Sachs, 1989; Smith and Rhode, 1989; Oertel et al., 1990; Blackburn and Sachs, 1992; Ferragamo et al., 1998).

\section{Materials and Methods}

Preparation. Electrophysiological experiments were performed on 20 male Hooded Wistar rats (250-350 gm). The main components of this protocol have been outlined previously (Paolini and Clark, 1999). These procedures were in accordance with the Royal Victorian Eye and Ear Hospital Animal Research Ethics Committee guidelines (project number 95037).

Animals were anesthetized with intraperitoneal aqueous urethane ( $20 \% \mathrm{w} / \mathrm{v}$ : total dose, $2.6 \mathrm{gm} / \mathrm{kg}$; Sigma, Sydney, Australia). After a craniotomy, the cerebellum was aspirated to expose the brainstem. Visualization of the $\mathrm{CN}$ at the lateral extreme allowed a recording electrode to be inserted into the left (ipsilateral) VCN in a caudorostral direction away from the octopus cell area. Placement of the stimulating electrode 
into the right (contralateral) VCN was also made under visual control. Both electrodes were stabilized in the tissue with $4 \%$ agar. Core body temperature, controlled by a DC homeothermic blanket, was maintained at $\sim 37^{\circ} \mathrm{C}$.

Recording. Microelectrodes (quartz thin-walled; $1.0 \mathrm{~mm}$ outer diameter; Sutter Instruments, Novato, CA), containing $1 \mathrm{~m}$ potassium acetate (KAc; $70-80 \mathrm{M} \Omega$ ) or $4 \%$ Neurobiotin (Vector Laboratories, Burlingame, CA) in 1 м KAc, were advanced through the VCN in $2 \mu \mathrm{m}$ steps by a motorized microdrive (Sutter Instruments). The concentric bipolar stimulating electrode (tungsten metal, $76 \mu \mathrm{m}$ core, 3-4 $\mu \mathrm{m}$ tip diameter; World Precision Instruments, Sarasota, FL) was advanced into the contralateral VCN until a small field potential was visible on the recording trace.

A "search stimulus" of $70-80 \mathrm{~dB}$ white noise ( 50 msec duration, every 500 $\mathrm{msec}$ ) was presented continuously to the ipsilateral side with advancement of the microelectrode. Intracellular stable impalements (typically possible for $10-90 \mathrm{~min})$ were signaled by a prolonged $(>3 \mathrm{~min})$, stable drop $(>30 \mathrm{mV})$ in the DC level and the presence of synaptic or large action potentials (APs) $(>20 \mathrm{mV})$ with monophasic rise and fall times. During stable cellular impalements, single shocks (typically from 10 to $600 \mu \mathrm{A}, 1 \mathrm{~Hz}$ presentation; charge balanced biphasic pulses, $100 \mu$ sec per phase) were delivered to the contralateral $\mathrm{CN}$, followed by acoustic stimuli (delayed $20-40 \mathrm{msec}$ ) presented to the left ear. Although we could not discount the possibility that electrical stimulation evoked the middle ear muscles through facial nerve activation, there is no evidence to suggest that such mechanisms are capable of decreasing the spontaneous activity of primary afferent inputs and therefore tonic drive to $\mathrm{CN}$ neurons.

After the generation of an antidromic AP, a collision test was performed, in which an ipsilaterally click-generated AP was presented at varying intervals before electrical stimulation. The characteristic frequency (CF) of the neuron and spike input-output (IO) function to CF tones were then determined. CF was calculated from a threshold tuning curve constructed online (Liberman, 1978). The IO function was constructed by presenting tones in $10 \mathrm{~dB}$ steps from subthreshold to saturation intensity. The stimulus consisted of a $50 \mathrm{msec}$ pure tone burst with a $5 \mathrm{msec}$ rise and fall time (to minimize the effect of transient components) and a $10 \mathrm{~Hz}$ repetition frequency. Acoustic stimuli (clicks, white noise, or tones) of varying intensities were also presented to the contralateral CN. Selected intracellular neurons were filled with Neurobiotin $(0.2-1 \mathrm{nA}$, $250 \mathrm{msec}$ positive pulses at $2 \mathrm{kHz} ; 2-10 \mathrm{~min}$ ). An electrolytic lesion was made in the contralateral $\mathrm{VCN}$ after recordings to verify the position of electrical stimulation $(20 \mu \mathrm{A} ; 2 \mathrm{~min})$.

Digitally synthesized acoustic stimuli were generated by Beyer DT48 transducers (Beyerdynamic, Farmingdale, NY), positioned at the end of the hollow ear bars and controlled using a Tucker-Davis signal generator (Tucker-Davis Technologies, Gainesville, FL). The acoustic system was calibrated using a Bruel \& Kjaer (B\&K) measuring amplifier (type 2606; Bruel \& Kjaer, Naerum, Denmark) and a B\&K $1 \frac{1}{2}$ inch condenser microphone, coupled to a small probe tube positioned $\sim 3 \mathrm{~mm}$ from the tympanic membrane. This enabled acoustic input to be measured in decibel sound pressure level (dB SPL). RMS levels of cross talk were measured to exclude indirect stimulation of the ipsilateral ear by contralateral acoustic stimuli and were found to vary in a complex frequency-dependent manner: attenuation of broadband stimuli was $55 \mathrm{~dB}$ and varied between 40 and $80 \mathrm{~dB}$ for pure frequencies.

The "Neurophysiology Laboratory System" of the Department of Otolaryngology (NLS software, by R. E. Millard, The University of Melbourne, Victoria, Australia), was used to control the Tucker-Davis unit and collate spike time information. Cellular responses were recorded using an Axoclamp 2B amplifier (Axon Instruments, Union City, CA), and electrophysiological traces were stored on a MacLab 4S system (ADInstruments, Sydney, Australia).

Classification. Neuron classification was made using neural discharge patterns displayed in poststimulus time (PST) and interspike interval (ISI) histograms constructed online (Pfeiffer, 1966). Firing regularity was assessed through the spike time coefficient of variation (CV) (Young et al., 1988; Blackburn and Sachs, 1989), calculated by dividing the SD by the mean ISI during successive $10 \mathrm{msec}$ time windows over the duration of the tone burst (50 stimulus repetitions). Neurons with $\mathrm{CV}$ values consistently $<0.3$ were classified as $\mathrm{C}_{\mathrm{S}}$. Neurons with a relatively low $\mathrm{CV}$
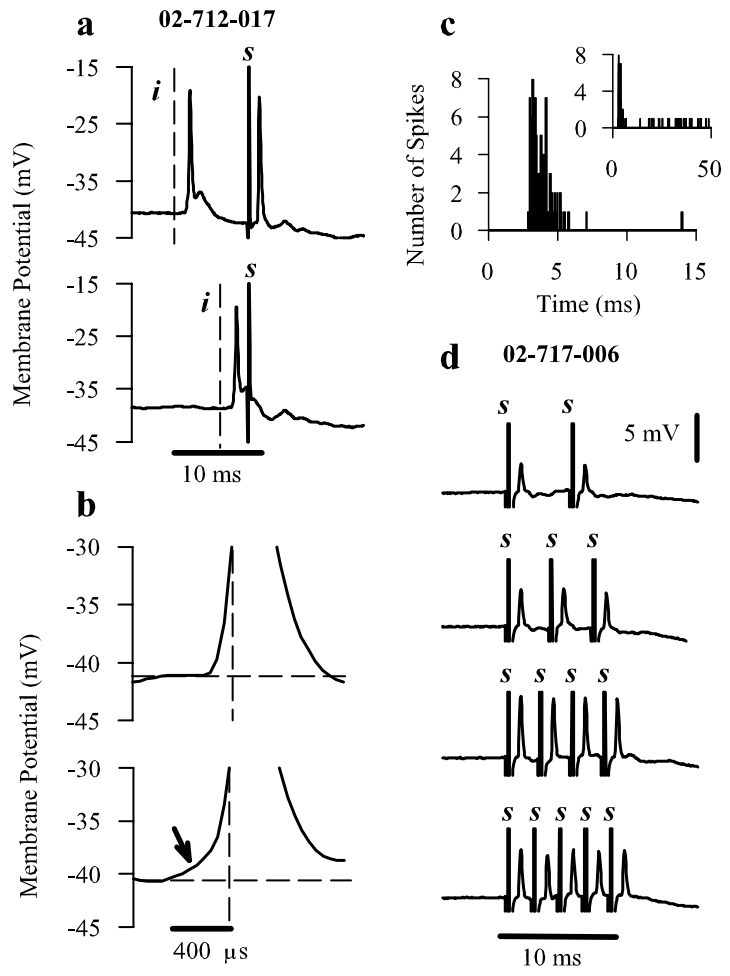

Figure 1. Electrically stimulated antidromic activity. a, Collision test performed on the intracellularly recorded $0_{C}$ neuron (02-712-017). The interval between ipsilateral click (vertical dashed line, denoted i) and contralateral electrical stimulation (artifact denoted s) was decreased from $8 \mathrm{msec}$ (top) to $3 \mathrm{msec}$ (bottom), thereby colliding the APs and eliminating the antidromic AP. $b$, The orthodromic AP (bottom), but not the antidromic AP (top), is accompanied by a spike prepotential (arrow) before activation. The vertical dotted line indicates time of maximal AP depolarization. The horizontal dashed line indicates resting membrane potential. APs are truncated for better illustration of depolarizing properties at AP onset. C, PST histograms constructed in response to suprathreshold (F tone bursts ( 50 repetitions) shown for the first 15 msec of presentation and $50 \mathrm{msec}$ (inset) provide confirmation of the response type of neuron 02-712-017. $d$, High-frequency electrical stimulation of an extracellularly recorded $0_{C}$ neuron (02-717-006) displaying antidromic activity.

value at onset, rising up to or above 0.3 from 20 to $50 \mathrm{msec}$ after onset, were classified as $\mathrm{C}_{\mathrm{T}}$. The $\mathrm{O}_{\mathrm{C}}$ response, from which $\mathrm{CV}$ calculations are difficult to obtain, were classified by the firing of two to four regularly spaced spikes, with little sustained activity thereafter. Intracellular neurons were classified on the basis of their intracellular response profile (Feng et al., 1994; Paolini et al., 1997; Paolini and Clark, 1999) and Neurobiotin-filled neurons by cellular morphology and dendritic arborizations (Wu and Oertel, 1984; Oertel et al., 1990).

\section{Results}

Intracellular recordings were taken from $18 \mathrm{VCN}$ neurons, and extracellular recordings were obtained for an additional nine. The mean resting membrane potential $( \pm \mathrm{SE}$ ) for intracellularly recorded neurons was $-51.3 \pm 1.57 \mathrm{mV}$, with an average $\mathrm{AP}$ amplitude of $39.9 \pm 2.61 \mathrm{mV}$ (range, $24-65 \mathrm{mV}$ ). Mean CF was $18.3 \pm 1.99 \mathrm{kHz}$, with a mean firing threshold of $38.1 \pm 5.53 \mathrm{~dB}$ SPL. Using aforementioned classification criteria, 15 neurons ( 14 intracellular and one extracellular) were identified as choppers, including both $\mathrm{C}_{\mathrm{S}}$ and $\mathrm{C}_{\mathrm{T}}$ subclasses, and 12 (four intracellular and eight extracellular) were classified as $\mathrm{O}_{\mathrm{C}}$ neurons.

\section{Antidromic activity in $\mathrm{O}_{\mathrm{C}}$ neurons}

Electrical stimulation of the contralateral $\mathrm{CN}$ often resulted in $\mathrm{AP}$ activation in $\mathrm{O}_{\mathrm{C}}$ neurons (Fig. 1). This activity was confirmed as antidromic in one (25\%) intracellular and six (75\%) extracellu- 
larly recorded $\mathrm{O}_{\mathrm{C}}$ neurons on the basis of four criteria (Kitai and Park, 1990). (1) Consistently short onset latency response (mean of $1.14 \pm 0.05 \mathrm{msec}$ ) is the first. (2) AP firing in an all-or-none manner, with stereotyped, invariant spike profiles, lacking spike prepotential is the second. Antidromic APs were differentiated from their orthodromic counterparts through the absence of a graded excitatory response before activation (Fig. 1b). (3) The third is elimination of the electrically evoked response through collision with an ipsilaterally activated orthodromic AP: the collision test (Fig. 1a). When the interval between ipsilateral click and electrical stimulus was less than the sum of the absolute refractory period of the orthodromic spike and the latency of the antidromic spike, the APs collided, preventing the antidromic AP from reaching the cell soma (Fig. 1a). (4) Maintenance of spike activity during high frequency electrical stimulation (Fig. $1 d$ ) is the fourth. Confirmation of the neuronal identity of the antidromically activated neuron displayed in Figure 1, $a$ and $b$, was provided by the PST histogram (Fig. 1c). The production of antidromic activity was not observed in any chopper neurons.

\section{Activation of commissural inhibition in chopper neurons}

The presence of short-latency membrane hyperpolarization (mean of $1.43 \pm 0.12 \mathrm{msec}$ onset) in response to contralateral electrical stimulation was observed in seven (50\%) intracellularly recorded chopper $\left(\mathrm{C}_{\mathrm{S}}\right.$ and $\left.\mathrm{C}_{\mathrm{T}}\right)$ neurons. As displayed by the intracellularly recorded $\mathrm{C}_{\mathrm{T}}$ neuron (intracellular profile, PST histogram, and CV) (Fig. 2a,b), large hyperpolarizing potentials were evoked with little delay $(1.1 \mathrm{msec})$ after electrical stimulation (Fig. 2c). Although the mean average maximum amplitude of hyperpolarization $(5.30 \pm 0.68 \mathrm{mV})$ across all chopper neurons was large, hyperpolarization amplitude within each neuron was dependent on stimulus strength (Fig. 2c). Examination of the mechanisms underlying the activation of electrically evoked hyperpolarization (Fig. $2 d, e$ ) through injection of hyperpolarizing and depolarizing current revealed a reversal of hyperpolarization between -68 and $-70 \mathrm{mV}$, results consistent with the reversal potential $(-67 \mathrm{mV})$ of glycinergic IPSPs in VCN neurons $(\mathrm{Wu}$ and Oertel, 1986). Thus, inhibition was identified as the source of hyperpolarization.

Whereas the short and highly consistent onset latency of hyperpolarization induced through electrical stimulation (Figs. 2, $3 c, f)$ indicated the monosynaptic nature of the commissural pathway [Power Test (Kitai and Park, 1990)], inhibition induced through contralateral acoustic clicks (Fig. $3 a, d$ ) was of a longer latency (mean of $3.55 \pm 0.06 \mathrm{msec}$ ) attributable to transmission through the cochlea and auditory nerve. Like IPSPs induced through electrical stimulation (Fig. 3b,e), hyperpolarization initiated by contralateral acoustic stimulation (Fig. $3 a, d$ ) was of a similar time course. However, the amplitude of hyperpolarization (mean average maximum, $3.53 \pm 0.64 \mathrm{mV}$ ) in response to contralateral clicks $(100 \mathrm{~dB})$ was consistently smaller than when stimulated electrically. Interestingly, hyperpolarization to acoustic stimulation was not seen in chopper neurons in which inhibition was not evoked by electrical stimulation. Furthermore, hyperpolarization was not evoked in $\mathrm{O}_{\mathrm{C}}$ cells in response to either electrical or acoustic stimuli, suggesting an absence of reciprocation between commissural neurons.

Inhibition in chopper neurons was also activated in response to broadband stimuli, such as noise (Fig. 4). Contralaterally presented white noise ( $80 \mathrm{~dB}$ SPL) induced short-latency $(4.2 \mathrm{msec})$ shortlived hyperpolarization (Fig. 4a1, arrow) in the $\mathrm{C}_{\mathrm{T}}$ neuron shown in Figure 2. The time course of this hyperpolarization (expanded time base) (Fig. $4 a 2$, asterisk) is similar to that seen in response to both

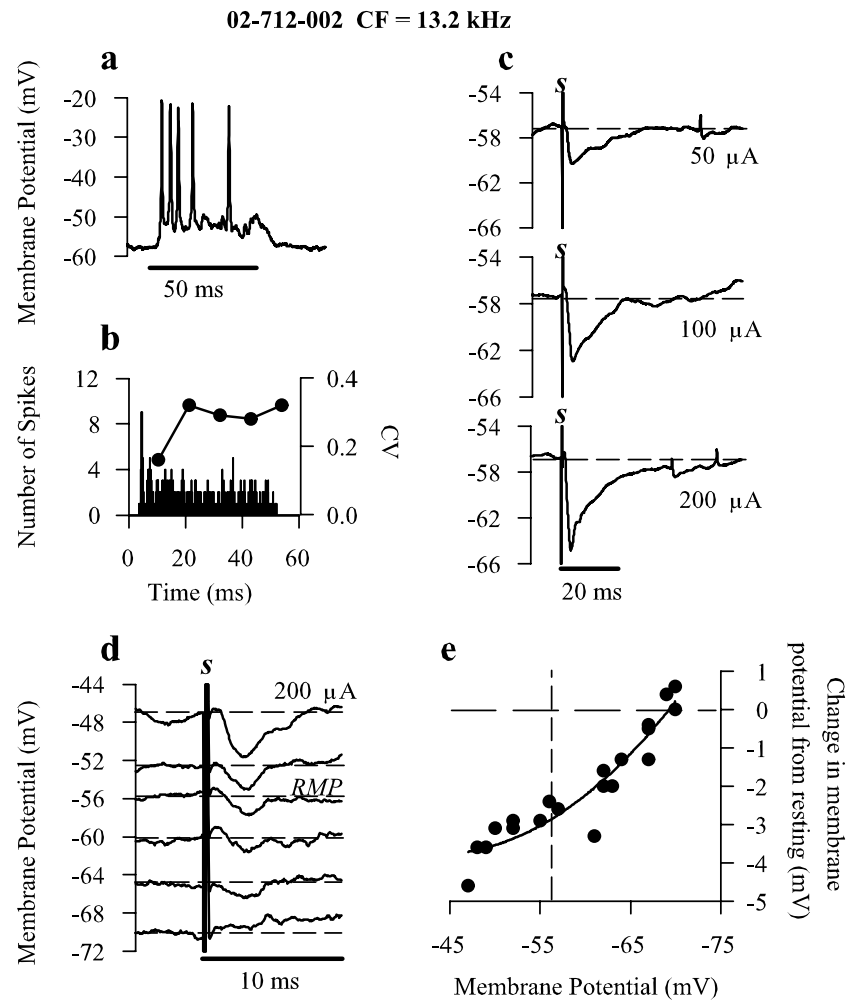

Figure 2. Initiation of hyperpolarization through contralateral electrical stimulation. $a$, Single intracellular response of neuron $02-712-002$ to suprathreshold $\mathrm{CF}(13.2 \mathrm{kHz}) 50$ msec tone bursts displaying a typical $C_{T}$ response pattern. $b$, PST histogram and $C V$ calculations of the response to $\mathrm{CF}$ tone bursts ( 50 repetitions). $c$, Increasing the strength of electrical stimulation $(50,100$, and $200 \mu \mathrm{A}$; artifact denoted s), as displayed in single intracellular traces, increases the amplitude of hyperpolarization. Horizontal dashed line indicates resting membrane potential. $d$, Effect of membrane potential on amplitude of hyperpolarization; intracellular traces at varying membrane potentials in response to electrical stimulation $(200 \mu \mathrm{A})$. Horizontal dashed lines indicate membrane potential at time of stimulation [resting membrane potential (RMP)]. Introducing negative current reduced the amplitude of hyperpolarization, with reversal of the membrane potential occurring between -68 and $-70 \mathrm{mV}$.e, Amplitude of hyperpolarization after electrical shock as a function of membrane potential for single responses of neuron shown in $d$. A negative change in the membrane potential from resting $(0 \mathrm{mV}$; horizontal dashed line) indicates hyperpolarization, whereas a positive value indicates depolarization. Vertical dashed line denotes resting membrane potential.

electrical and acoustic click stimulation (Figs. 2, 3). However, hyperpolarization initiated by noise was soon exceeded by excitatory inputs ( $\sim 14$ msec after onset), presumably provided via polysynaptic pathways originating from higher auditory centers or the excitatory collaterals of local T stellate neurons (Ferragamo et al., 1998). In contrast, contralateral pure tones presented at frequencies close to the CF of the isolated neuron (Fig. 4b1-b4) initiated no IPSPs. This most likely reflects a lack of tonotopic alignment between commissural neurons and their ipsilateral targets rather than an inability to induce neuronal activity through pure tones alone. Instead, periods of sustained depolarization were observed in response to near-CF (Fig. 4b3) and below-CF (Fig. 4b2) tones, with an onset latency (7 $\mathrm{msec}$ ) consistent with polysynaptic drive. It is unlikely that this excitation is attributable to cross talk given the level of attenuation of contralateral sounds recorded ipsilaterally. Whereas the stimulus intensity presented ( $80 \mathrm{~dB}$ SPL) was high, the intensity of contralateral stimuli required to reach threshold of this neuron was $98 \mathrm{~dB}$ SPL.

In addition, high-frequency electrical stimulation was used to simulate the effects of $\mathrm{O}_{\mathrm{C}}$ activity on the behavior of hyperpolarization in chopper neurons (Fig. 4c). As the stimulation frequency increased from 200 to $500 \mathrm{~Hz}$ (two to five pulses; $100 \mu \mathrm{A}$ ), 


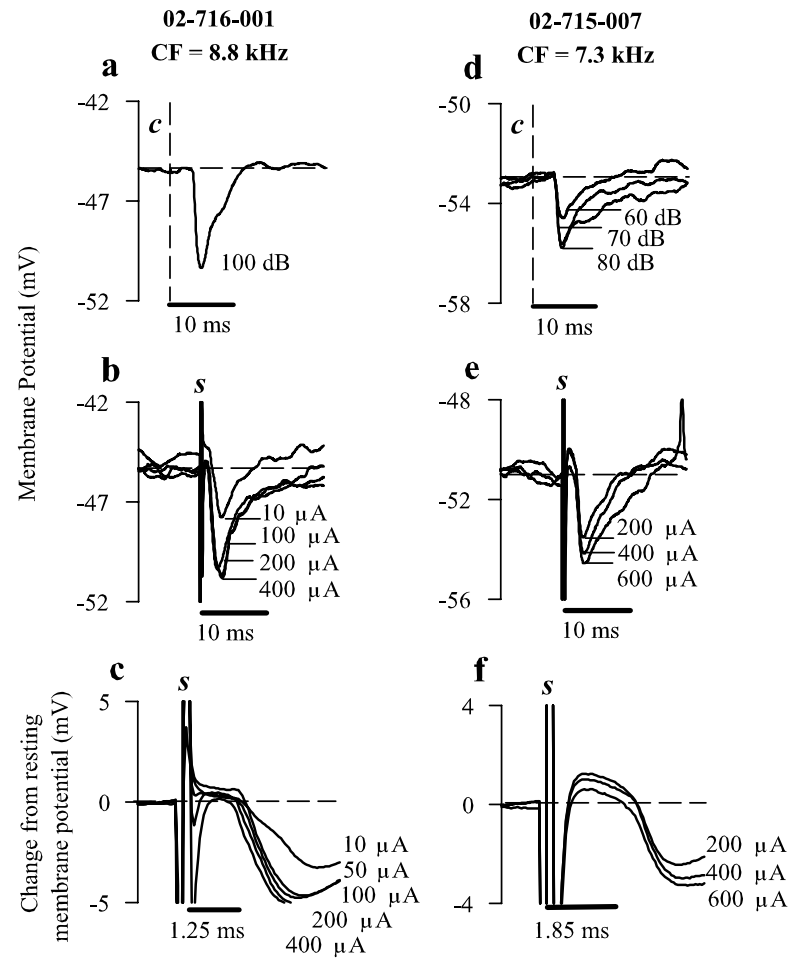

Figure 3. Inhibition through acoustic and electrical stimulation. $a, I P S P$ produced in $C_{T}$ neuron 02-716-001 after a $100 \mathrm{dBSPL}$ contralateral click (dashed vertical line denoted c). Horizontal dashed line indicates resting membrane potential. $b$, IPSPs resulting from electrical stimulation (stimulus artifact denoted s) of the contralateral CN $(10,100,200$, and $400 \mu \mathrm{A}) . c$, Expanded time base of responses shown in $b$, with membrane potential standardized to zero demonstrating the synchronization of IPSP onset latency across varying stimulus strengths. $d$, Change in hyperpolarization amplitude in response to changing strength of contralateral acoustic click $(60,70$, and $80 \mathrm{~dB})$, represented in averaged intracellular traces from $C_{s}$ neuron 02-715-007. $e_{\text {, }}$ Average intracellular responses to increasing levels of contralateral electrical stimulation (200, 400 , and $600 \mu \mathrm{A}) . f$, Expanded time base of responses shown in e, standardized as in c.

the IPSPs summated, resulting in longer periods of inhibition (Fig. 4c), thereby indicating that the behavior of inhibition initiated by $\mathrm{D}$ stellate neurons is dependent on the extent of the intrinsic firing activity.

\section{Discussion}

Combining in vivo intracellular electrophysiological recordings with electrical and acoustic stimulation of the contralateral $\mathrm{CN}$, this study is the first to demonstrate a fast, monosynaptic inhibitory commissural connection between cochlear nuclei. The isolation of inhibitory potentials in VCN neurons after stimulation of the contralateral $\mathrm{CN}$ has permitted the nature and behavior of the commissural pathway to be examined in a manner not permitted by previous methods of investigation.

\section{Commissural inhibition}

Inhibitory responses exhibiting monosynaptic transmission from the contralateral $\mathrm{CN}$ were detected in neurons responding to ipsilateral tones in a chopping $\left(\mathrm{C}_{\mathrm{S}}\right.$ or $\left.\mathrm{C}_{\mathrm{T}}\right)$ manner. The input of commissural inhibitory projections to chopper neurons, associated with the T stellate population, confirms anatomical observations (Schofield and Cant, 1996a,b) that T stellate cells receive strong inhibitory commissural input. Furthermore, these results are consistent with evidence indicating the connection to be glycinergic and inhibitory (Wenthold, 1987; Benson and Potashner, 1990; Babalian et al., 1999, 2002).

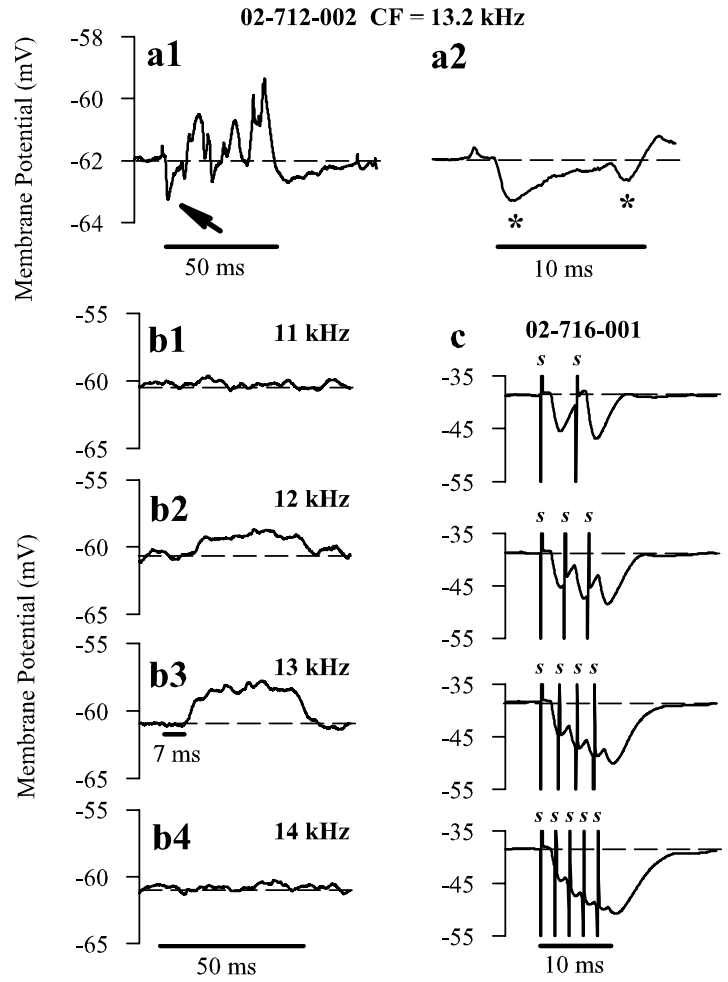

Figure 4. Chopperneuron responses to contralateral broadband stimuli and high-frequency electrical stimulation. a1, Average intracellular response of a $C_{T}$ neuron (02-712-002) to the presentation of a contralateral $50 \mathrm{msec} 80 \mathrm{~dB}$ white noise burst (over 50 repetitions). Arrow indicates period of sustained hyperpolarization after contralateral presentation. $a 2$, The first 30 msec of the average response displayed in a1; asterisks denote periods of hyperpolarization similar in time course to those displayed in response to electrical stimulation (Fig. 3). Horizontal dashed lines indicate resting membrane potential.b1-b4, Response of neuron 02-712-002 (CF of $13.2 \mathrm{kHz}$ ) to 50 msec pure tone bursts (averaged over 50 repetitions) below CF (11 and $12 \mathrm{kHz}$ ), near CF (13 kHz), and above CF (14 kHz). C, Average response of neuron 02-716-001 to train of multiple electrical pulses of $100 \mu \mathrm{A}$ presented with increasing frequency $(200,300,400$, and $500 \mathrm{~Hz})$.

Conversely, the activation of antidromic APs in response to electrical stimulation indicated that the projections of $\mathrm{O}_{\mathrm{C}}$ neurons terminate in the contralateral $\mathrm{VCN}$. These results, given the association between the $\mathrm{O}_{\mathrm{C}}$ response and $\mathrm{D}$ stellate neurons (Oertel et al., 1990; Paolini and Clark, 1999), support previous findings (Cant and Gaston, 1982; Schofield and Cant, 1996a,b) suggesting that large multipolar cells, correlating to the D stellate population (Oertel et al., 1990), are responsible for the inhibitory pathway. This is also consistent with evidence that both D stellate cells (Doucet et al., 1999) and commissural neurons (Wenthold, 1987; Babalian et al., 2002) possess glycinergic projections.

The presence of antidromic activity in a small proportion of $\mathrm{O}_{\mathrm{C}}$ responses may reflect either (1) an inability to activate all D stellate cells through electrical stimulation, or (2) the presence of contralateral projections in only a subset of the population. Although the latter hypothesis cannot be confirmed nor refuted by the results, the first scenario appears less likely because acoustically evoked inhibition was only observed in those chopper neurons also inhibited by electrical stimulation. Although inhibition evoked through both electrical and acoustic means exhibited IPSPs of similar time course, differences in amplitude suggest that antidromically activated D stellate collaterals synapsing intrinsically within the VCN may contribute some inhibitory input during electrical stimulation. 


\section{Fast, monosynaptic pathway}

This study provides definitive evidence to support the fast, monosynaptic nature of the commissural pathway. The results presented here consistently demonstrate the activation of shortlatency (mean of $1.43 \mathrm{msec}$ ) hyperpolarization in response to electrical stimulation. Similarly, acoustic stimuli presented to the contralateral ear produced short-latency (mean of $3.55 \mathrm{msec}$ ) responses, reflecting the activation of synaptic relays through the cochlea and auditory nerve. Because $\mathrm{O}_{\mathrm{C}}$ ipsilaterally induced APs are activated $\sim 3 \mathrm{msec}$ after acoustic presentation (Rhode and Smith, 1986; Paolini and Clark, 1999) (Fig. 1a,c), we can assume that the extra delay associated with contralateral acoustic stimulation involves only one additional synaptic event, the commissural pathway. A comparison of latency between antidromic activation $(1.14 \mathrm{msec})$ and inhibition produced from contralateral electrical stimulation $(1.43 \mathrm{msec})$ implies that the synaptic delay involved in the conduction of commissural inhibition is in the order of $0.3 \mathrm{msec}$. Moreover, the time course of IPSPs indicates that they are fast acting (duration typically $<10 \mathrm{msec}$ ).

\section{Functional implications}

Although the influence of a single IPSP is transient, the overall extent of inhibition is essentially dependent on the intrinsic firing behavior of the $\mathrm{D}$ stellate neuron. As exhibited by our results, inhibition is most evident when activated through broadband stimuli, to which $\mathrm{O}_{\mathrm{C}}$ neurons respond most vigorously. Given that inhibition is postulated to influence the regularity of chopping activity in chopper neurons (Blackburn and Sachs, 1989; Banks and Sachs, 1991), the fast transmission of inhibitory input from contralateral D stellate cells could directly affect the timing and synchrony of chopping behavior in T stellate neurons. Furthermore, the introduction of broadband inhibition to the narrowly tuned T stellate population, like that provided by intrinsically projecting D stellate neurons (Ferragamo et al., 1998), most likely contributes to the production of inhibitory sidebands. Activation of commissural inhibition could therefore both sharpen the coding of spectral peaks in T stellate neurons through lateral inhibition (Rhode and Greenberg, 1994) and modify their chopping behavior. Thus, binaural processing at the level of the VCN may contribute to improved coding of spectral peaks in background noise.

\section{References}

Alibardi L (1998) Ultrastructural and immunocytochemical characterization of commissural neurons in the ventral cochlear nucleus of the rat. Anat Anz 180:427-438.

Alibardi L (2000) Putative commissural and collicular axo-somatic terminals on neurons of the rat ventral cochlear nucleus. J Submicrosc Cytol Pathol 32:555-566.

Babalian AL, Ryugo DK, Vischer MW, Rouiller EM (1999) Inhibitory synaptic interactions between cochlear nuclei: evidence from an in vitro whole brain study. NeuroReport 10:1913-1917.

Babalian AL, Jacomme AV, Doucet JR, Ryugo DK, Rouiller EM (2002) Commissural glycinergic inhibition of bushy and stellate cells in the anteroventral cochlear nucleus. NeuroReport 13:555-558.

Banks MI, Sachs MB (1991) Regularity analysis in a compartmental model of chopper units in the anteroventral cochlear nucleus. J Neurophysiol 65:606-629.

Benson CG, Potashner SJ (1990) Retrograde transport of $\left[{ }^{3} \mathrm{H}\right]$ glycine from the cochlear nucleus to the superior olive in the guinea pig. J Comp Neurol 296:415-426.

Blackburn CC, Sachs MB (1989) Classification of unit types in the anteroventral cochlear nucleus: PST histograms and regularity analysis. J Neurophysiol 62:1303-1329.

Blackburn CC, Sachs MB (1992) Effects of OFF-BF tones on responses of chopper units in ventral cochlear nucleus. I. Regularity and temporal adaptation patterns. J Neurophysiol 68:124-143.

Cant NB, Gaston KC (1982) Pathways connecting the right and left cochlear nuclei. J Comp Neurol 212:313-326.

Doucet JR, Ross AT, Gillespie MB, Ryugo DK (1999) Glycine immunoreactivity of multipolar neurons in the ventral cochlear nucleus which project to the dorsal cochlear nucleus. J Comp Neurol 408:515-531.

Feng JJ, Kuwada S, Ostapoff EM, Batra R, Morest DK (1994) A physiological and structural study of neuron types in the cochlear nucleus. I. Intracellular responses to acoustic stimulation and current injection. J Comp Neurol 346:1-18.

Ferragamo MJ, Golding NL, Oertel D (1998) Synaptic inputs to stellate cells in the ventral cochlear nucleus. J Neurophysiol 79:51-63.

Kitai ST, Park MR (1990) Intracellular Electrophysiological Techniques. In: Neuromethods: neurophysiological techniques (Boulton AA, Baker GB, Vanderwolf CH, eds), pp 1-34. Clifton, NJ: Humana.

Klinke R, Boerger G, Gruber J (1969) Studies on the functional significance of efferent innervation in the auditory system: afferent neuronal activity as influenced by contralaterally applied sound. Pflügers Arch 306:165-175.

Liberman MC (1978) Auditory-nerve response from cats raised in a lownoise chamber. J Acoust Soc Am 63:442-455.

Mast TE (1970) Binaural interaction and contralateral inhibition in dorsal cochlear nucleus of the chinchilla. J Neurophysiol 33:108-115.

Mast TE (1973) Dorsal cochlear nucleus of the chinchilla: excitation by contralateral sound. Brain Res 62:61-70.

Oertel D, Wu SH, Garb MW, Dizack C (1990) Morphology and physiology of cells in slice preparations of the posteroventral cochlear nucleus of mice. J Comp Neurol 295:136-154.

Paolini AG, Clark GM (1999) Intracellular responses of onset chopper neurons in the ventral cochlear nucleus to tones: evidence for dualcomponent processing. J Neurophysiol 81:2347-2359.

Paolini AG, Clark GM, Burkitt AN (1997) Intracellular responses of the rat cochlear nucleus to sound and its role in temporal coding. NeuroReport 8:3415-3421.

Pfalz RKJ (1962) Centrifugal inhibition of afferent secondary neurons in the cochlear nucleus by sound. J Acoust Soc Am 34:1472-1477.

Pfeiffer RR (1966) Classification of response patterns of spike discharges for units in the cochlear nucleus: tone-burst stimulation. Exp Brain Res 1:220-235.

Rhode WS, Greenberg S (1994) Lateral suppression and inhibition in the cochlear nucleus of the cat. J Neurophysiol 71:493-514.

Rhode WS, Smith PH (1986) Encoding timing and intensity in the ventral cochlear nucleus of the cat. J Neurophysiol 56:261-286.

Schofield BR, Cant NB (1996a) Projections from the ventral cochlear nucleus to the inferior colliculus and the contralateral cochlear nucleus in guinea pigs. Hear Res 102:1-14.

Schofield BR, Cant NB (1996b) Origins and targets of commissural connections between the cochlear nuclei in guinea pigs. J Comp Neurol 375:128-146.

Shore SE, Godfrey DA, Helfert RH, Altschuler RA, Bledsoe SC Jr (1992) Connections between the cochlear nuclei in guinea pig. Hear Res 62:16-26.

Smith PH, Rhode WS (1989) Structural and functional properties distinguish two types of multipolar cells in the ventral cochlear nucleus. J Comp Neurol 282:595-616.

Wenthold RJ (1987) Evidence for a glycinergic pathway connecting the two cochlear nuclei: an immunocytochemical and retrograde transport study. Brain Res 415:183-187.

Wu SH, Oertel D (1984) Intracellular injection with horseradish peroxidase of physiologically characterized stellate and bushy cells in slices of mouse anteroventral cochlear nucleus. J Neurosci 4:1577-1588.

Wu SH, Oertel D (1986) Inhibitory circuitry in the ventral cochlear nucleus is probably mediated by glycine. J Neurosci 6:2691-2706.

Young ED (1998) Cochlear nucleus. In: The synaptic organization of the brain, Ed 4 (Shepherd GM, ed), pp 121-157. New York: Oxford UP.

Young ED, Brownell WE (1976) Responses to tones and noise of single cells in dorsal cochlear nucleus of unanesthetized cats. J Neurophysiol 39:282-300.

Young ED, Robert JM, Shofner WP (1988) Regularity and latency of units in ventral cochlear nucleus: implications for unit classification and generation of response properties. J Neurophysiol 60:1-29. 